\title{
Cross-Cultural Digital Storywork: A Framework for Engagement with/in Indigenous Communities
}

\author{
Christine Rogers Stanton, Brad Hall, Lucia Ricciardelli
}

\begin{abstract}
Aвstract While Indigenous peoples have long urged attention to Six Rs (respect, relevance, reciprocity, responsibility, relationality, and representation) that are important to community-engaged work, application of these principles has been sporadic within the filmmaking industry. Many Indigenous communities do not have the technical expertise and/or resources needed to support professional quality audiovisual production. As a result, they rely on predominantly White filmmakers from beyond the community. Unfortunately, mainstream filmmaking practices have historically demonstrated a disregard for Indigenous ways of knowing, and a scarcity of meaningful relationships between filmmakers and community members has further contributed to a legacy of insensitive filmmaking within Indigenous contexts. In addition, internet-based distribution of cultural content raises questions about post-production sovereignty. In this project, Tribal College (TC) students and faculty partnered with students and faculty from a Predominantly White Institution (PWI) to develop culturally sustaining and revitalizing documentaries using storywork, digital storytelling, ethnocinema, and community-centered participatory research. Throughout the Digital Histories Project, TC participants gained technical expertise, PWI participants learned about culturally sustaining/revitalizing filmmaking, and faculty leaders identified ways to support use of the Six Rs within social science, history, and teacher education. Results offer methodological and pedagogical insights for scholars, educators, tribal leaders, and filmmakers.
\end{abstract}

KEYWords Indigenous; Native; documentary filmmaking; story; participatory

"The truth about stories is that that's all we are."

(Thomas King, 2003, The Truth About Stories, p. 2)

Stories shape our individual and collective histories, and they are central to our cultural identities. Within Indigenous ${ }^{1}$ communities, stories have served to sustain Native knowledges in spite

\footnotetext{
1 While it is preferable to refer to groups using specific tribal or community names, especially if those names represent the traditional names the people of those groups gave themselves (e.g. "Apsaalooke" or "Piikani"), it is not always appropriate within scholarly contexts. Such specificity can compromise privacy and culturally sensitive understandings, particularly given the small populations within many Indigenous communities. In work that strives to advance broader methodological and/or theoretical practices, using more general terms can be a way to demonstrate unity across diverse tribal communities. However, the danger is that such generalization might suggest a lack of inter- and intra-tribal diversity. To protect specific communities,
} 
of centuries of efforts to assimilate, oppress, terminate, and colonize the First Peoples of the Americas. Over the past two decades, digital approaches to the telling and sharing of stories have presented new possibilities and new challenges. For example, though documentaries that are disseminated via social media offer opportunities for great numbers of people all over the world to share and access information in a timely manner, they can also result in inappropriate diffusion of culturally sensitive content.

To promote culturally responsive storytelling, research, and education, Indigenous communities have long urged attention to Four Rs (respect, relevance, reciprocity, and responsibility) (Kirkness \& Barnhardt, 2001). Unfortunately, within the film industry in the United States, application of these principles has proven challenging due to a legacy of stereotypical representations and a scarcity of meaningful relationships between predominantly White filmmakers and Indigenous communities (Kilpatrick, 1999; Seixas, 2007; Stoddard, Marcus, \& Hicks, 2014). The purpose of this article is to highlight efforts to advance culturally sustaining and revitalizing education (McCarty \& Lee, 2014) and scholarship through a crosscultural documentary project.

As part of the Digital Histories Project, Tribal College (TC) students and faculty partnered with students and faculty from a Predominantly White Institution (PWI) (Willie, 2003). The Project's goals included: 1) to cultivate meaningful cross-cultural relationships; 2) to provide TC participants access to semi-professional filmmaking equipment and technical expertise needed to serve their community; 3) to prepare PWI participants to advocate for culturally sustaining/revitalizing filmmaking; and 4) to help faculty advance culturally sustaining/ revitalizing education and research within social science, history, and teacher education. Broadly, this article addresses the question: How can digital cross-cultural storywork advance the goals of Indigenous Research Methodologies, culturally sustaining/revitalizing education, and community-engaged scholarship?

\section{Theoretical Framework}

Indigenous Research Methodologies (IRMs) provided the foundation for the Project's design. As McGregor and Murnane (2010) note, methodology refers to the broader philosophies underlying research, while methods "are the techniques and procedures followed to conduct research, and are determined by the methodology" (p. 2). While IRMs provide a framework to guide the development, selection, and application of methods, it is important to note that they are not in and of themselves set, prescriptive methods. Instead, they offer a methodological orientation to research, learning, and filmmaking that supports culturally sensitive decisionmaking throughout the process. Although multiple scholars and Indigenous communities have contributed in unique ways to the development of IRMs, there are areas of intersectionality, including calling for practice that is critical, action-oriented, and aligned with traditional Indigenous knowledges/ways of knowing (Brayboy, Gough, Leonard, Roehl, \& Solyom, 2012;

encourage theoretical and methodological unity, and remind readers of the diversity within and across communities, this article alternates between "Indigenous," "First Nations," "Native," and "tribal" and uses plural forms to refer to peoples, knowledges, histories, experiences, and communities.

Engaged Scholar Journal: Community-Engaged Research, Teaching and Learning 
Kirkness \& Barnhardt, 2001; Kovach, 2009; Wilson, 2008), and recognizing the importance of story as method and as counter-narrative to settler-colonial understandings (Brayboy, 2005; Grande, 2008; Kovach, 2009; Smith, 1999).

Wilson (2008) builds on the Four Rs (respect, reciprocity, responsibility, and relevance) identified by Kirkness and Barnhardt (2001) by noting the need for Indigenous scholars to consider research as a cultural responsibility grounded in collectivity and relationality. Kovach (2009) argues that Indigenous research differs from most Western research given its relational and participatory demands. Brayboy et al. (2012) emphasize the need for scholarship that advances community participation and an emancipatory agenda.

Brayboy (2005) highlights the need for Native counter-narratives - stories that offer an alternative to as well as a critique of settler-colonial perspectives-within educational research in his argument for Tribal Critical Race Theory (TribalCrit). Grande (2008) also notes the power of story through Red Pedagogy, as a means to critically interrogate mainstream understandings of teaching and learning. In Decolonizing Methodologies, Smith (1999) encourages research that expands participation of Indigenous community members and elevates attention to story. However, Smith also cautions that Indigenous stories, especially those shared via digital media and the Internet, can affect entire Indigenous communities in either positive or negative ways, so they must be shared only after collaboration with community leaders.

Throughout educational research, critical scholars have encouraged attention to historically marginalized cultural knowledges (González, Moll, \& Amanti, 2005; Paris, 2012). McCarty and Lee (2014) propose Culturally Sustaining/Revitalizing Pedagogy (CSRP), which emphasizes purposeful efforts to reinvigorate traditional Indigenous knowledges, both within Indigenous communities and within cross-cultural contexts. CSRP recognizes the importance of community-based accountability, particularly as related to tribal sovereignty. Through collaboration with Native communities, educators-including non-Native teachers-can identify, confront, and resist colonizing influences that continue to affect decision-making related to teaching and learning. Both Indigenous and non-Indigenous educators are important in terms of decolonizing education and research, especially given the small number of Indigenous peoples currently engaged in teaching and educational research (Kovach, 2013).

To advance CSRP, the Digital Histories Project synthesized these key understandings from across the Indigenous educational research literature. In particular, the Project endeavored to engage Native participants as active decision-makers throughout the research and storytelling processes. To challenge narrow views of research and film production, the Project focused on aligning methodologies, methods, and Indigenous ways of knowing. To guide this alignment, we applied a framework consisting of six Rs (respect, relevance, reciprocity, responsibility, relationality, and representation) identified by Indigenous scholars and reaffirmed by Indigenous community members participating in the Project. We discuss and contexualize each of these Rs in the "Storywork for Sovereignty" section below.

\section{Methods: Attention to Community-Engaged Process}

It is important to note that the project outlined in this article is not meant to serve as a 
prescriptive toolkit, but rather as a means to illustrate application of IRMs using a specific example. Within our unique contexts (a TC located on a reservation in the Northern Plains of the U.S. and a PWI located approximately 250 miles from the reservation), elements of Indigenous storywork, digital storytelling, ethnocinema, and community-centered participatory research informed the design of the Digital Histories Project. When integrated, these methods promote a shift of control from the typically White scholar/filmmaker to Native communities. In addition, combining these methods supports inquiry into learning and research processes, given their inherent attention to the ways that values and beliefs influence decision-making. Within cross-cultural contexts, in particular, this combination offers the potential to advance culturally sustaining and revitalizing education, given its potential to engage non-Indigenous allies with Indigenous communities (Kovach, 2009).

For the Project, Archibald (2008)'s Indigenous Storywork guided the research and storytelling processes. As Archibald emphasizes, story and culture are inseparable within Indigenous communities, and learning through story is central to sustaining and revitalizing cultural knowledges. Given this integrated and iterative nature of storywork, it is important for scholars-and all learners-to engage dynamically with multiple community members throughout the development and dissemination of cultural stories. Within storywork, the process of storying is as important as the product of the story itself.

Iseke and Moore (2011) highlight several Indigenous digital storytelling projects that foster collaboration, benefit Indigenous communities, and promote learning across and between generations. As Iseke and Moore (2011) explain, "Indigenous digital storytelling integrates indigenous stories and sacred places and artifacts in innovative ways, is created by and for indigenous communities, addresses change, reflects community knowledge and perspectives, and enables negotiation of the community's social priorities" (p. 32). Indigenous digital storywork, therefore, differs from mainstream filmmaking approaches, which have historically excluded members of Indigenous communities at various stages of the production process. The examples provided by Iseke and Moore (2011) offered guidance for the Digital Histories Project in terms of involving community members throughout the process, editing footage for effect without compromising the integrity of stories, and honoring nonlinear story structures.

Ethnocinema is related to both storywork and Indigenous digital storytelling, although it differs in its cross-cultural focus. Ethnocinema can be broadly defined as ethnographic documentary filmmaking, or, more specifically, as a "qualitative method of intercultural collaboration [which] prioritizes creativity, mutual identity construction, and the principles of critical theory" (Harris, 2010, p. 769). Harris also notes that ethnocinema emphasizes process, as well as product. In other words, ethnocinema is a departure from the majority of filmmaking efforts within Indigenous communities in that it is not merely about the finished film: It is about the relationships formed and the mutual meaning-making throughout the planning, filming, and editing processes.

Community-centered participatory research values methods that are collaborative, that are guided by community interests, and that engage community members as co-scholars in placeconscious learning (Gruenewald, 2003; Israel, Schulz, Parker, \& Becker, 1998; Northway, 2010;

Engaged Scholar Journal: Community-Engaged Research, Teaching and Learning 
Stanton, 2014). Depending upon community needs and values, co-scholars may select a variety of methods to guide the process. In this project, elements of storywork, digital storytelling, and ethnocinema informed the research design, with the principles of community-centered participatory research guiding the application of those methods within our specific context.

While Iseke and Moore (2011) identify as Indigenous and work with members of their own communities on digital storytelling projects, the Digital Histories Project team consists of both Native and non-Native filmmakers, scholars, students, and faculty leaders. Such a composition creates both new challenges and new opportunities for ethnocinema and digital storywork. Several years ago, the TC faculty leader began thinking about a collaboration that would support the exchange of cultural and technical expertise. From the Project's inception, the faculty leaders recognized the importance of these diverse forms of expertise: The TC is on the leading edge of community-based Indigenous research, and the PWI offers an internationally renowned program in film. Together, we believed we could develop a crosscultural model that would advance culturally sustaining and revitalizing education for both Native and non-Native peoples.

Project participants included faculty and undergraduate students from the TC and PWI, graduate students and recent graduates of the PWI, Native scholars, and tribal community members. The TC faculty leader identifies as Native, and he is a well-respected member of the tribal community. The TC student participants also identify as Native, and several consider themselves to be "traditional" in terms of practicing cultural beliefs. Both PWI faculty leaders - one a professor of education and one a professor of film-identify as White women who have experience studying and teaching about colonization and culturally responsive pedagogy. All twenty PWI student participants, who enrolled in a film seminar, identify as White. Most are not originally from the area, and only one had experience working with Indigenous communities prior to the start of the Project.

The Project consisted of a planning phase, five workshops (two based at the PWI and three based at the TC), and a community showcase. While the entire process spanned two years, the series of workshops and the community showcase occurred during a short time frame of nine months. The first workshop introduced TC and PWI participants to the Six Rs and a variety of documentary filmmaking modes. Participants then formed teams to share storytelling ideas and develop storyboards. The workshop concluded with an orientation to the filming equipment (i.e. camera, tripod, and lighting/sound equipment). The second workshop began with a discussion of research ethics in tribal communities and the role of the Six Rs in guiding Project decision-making. The PWI participants then shared "Storyarc PowerPoints" and mentored the TC participants as they developed their own PowerPoints to refine project planning. The second half of the workshop focused on an introduction to iMovie editing software and guided practice using the camera.

Originally, the Project leadership team planned to hold the first two workshops in the tribal community. We changed the location to the PWI for several reasons, including limited funding (e.g. we would have been able to support travel for only a few of the PWI students enrolled in the seminar, which would have reduced participation) and expanded availability of filmmaking 
technology (e.g. at the PWI, we had access to semi-professional camera equipment, lighting kits, and computers with editing software). Following the second workshop, we discussed an additional, unexpected benefit of holding the first workshops at the PWI: The Project format allowed PWI students to develop relationships with TC participants before traveling to the tribal community. Our prior experience leading short-term, reservation-based experiences for PWI students suggests that such experiences can reinforce stereotypes rather than challenge them, especially given the influence of stereotypical imagery within popular media. Since the Digital Histories Project focused on building relationships first, the PWI participants who attended the third, fourth, and/or fifth workshops felt more comfortable asking questions and confronting stereotypes.

The third workshop, which was based in the tribal community, provided targeted and individualized mentorship. PWI participants helped TC participants address footage challenges, practice interviewing skills, and refine use of software and equipment. The fourth and fifth workshops, also held at the tribal college, focused on editing and finalizing digital stories in preparation for the community showcase. The showcase, which was held in conjunction with a four-day community-wide cultural and research celebration, included an overview of the process as well as the premiere of one of the student-created films.

In addition to the formal workshops, much of the cross-cultural learning occurred in informal settings, such as during meals. At the end of the second workshop, the PWI faculty leaders hosted a dinner at one leader's home. This was an event that proved to be a highlight of the Project for PWI and TC students and faculty alike. Dinners involving participants and family members were also held during the third and fourth workshops. A celebratory dinner followed the community showcase at the end of the fifth workshop.

Multiple forms of data contributed to the study of the Project, including planning materials, workshop observations, researcher memos, focus groups, interviews, workshop artifacts (e.g. video products, storyboards), and social media exchanges. A combination of open and focused coding was used to analyze the field note, artifact, interview, and focus group data (Emerson, Fretz, \& Shaw, 1995; Rubin \& Rubin, 2005). In addition to the faculty researchers, the student participants contributed to analysis. For example, workshop artifacts included storyboards (visual templates to guide organization and film planning) and theme cards (identifying key themes from footage). The TC students interpreted these artifacts, instead of the faculty researchers. As a result, it became clear that the TC participants interpreted data differently from PWI students and researchers. For example, the TC participants recognized the cultural significance of certain allusions and elements unknown to the non-Native researchers.

To further refine themes, the faculty researchers applied the Six R framework for focused coding. This framework emerged as the result of combining the Four Rs identified by Kirkness and Barnhardt (2001) with two additional Rs (relationality and representation) discussed by tribal members and student participants during the first workshop and emphasized across the literature describing IRMs. These Six Rs frame discussion of findings (see below). 


\section{Storywork for Sovereignty: Applying the 6 Rs to Research}

The Project's main purpose was to support development of Indigenous researchers who are able to use filmmaking to tell their communities' stories in ways that are culturally appropriate and high in technical quality. While both TC and PWI participants engaged in documentary storywork, all major content and procedural decisions remained under the control of the Native participants. Therefore, the findings we share here focus primarily on the process that guided the Project, rather than the content of the resulting products (i.e. student documentaries), since that content remains in the control of the tribal community.

\section{Respect}

Respect for Indigenous knowledges and ways of knowing is fundamental to IRMs. Wilson (2008) notes that respect demands deep listening and sustained engagement with community members. Brayboy (2005) emphasizes that respecting Indigenous knowledges relies upon appreciation for story and storytelling. Respect for Indigenous worldviews is not only essential to sustainability and revitalization of cultural knowledges; it is also important for the retention of Indigenous students in higher education. Kirkness and Barnhardt (2001) explain that a lack of respect for Indigenous "cultural knowledge, traditions, and core values" constitutes "the most compelling problem that First Nations students face when they go to the university" (p. 6). Engaging in collaborative, participatory scholarship can offer a way to integrate Indigenous values and traditions more effectively into cross-cultural learning contexts, such as PWIs.

Several examples from the Project highlight the potential for cross-cultural storywork to promote respect for Indigenous knowledges and ways of knowing throughout the documentary filmmaking and research processes. Before the first workshop, the PWI and TC faculty members led activities related to perspective within visual media, cultural bias and stereotyping, and the importance of deep listening. The TC students met weekly to build rapport, share film ideas, and discuss their concerns about collaborating with the PWI students. The PWI students met as a class, where they learned about the importance of identifying and confronting romanticized and stereotypical perspectives of Native stories. For example, the PWI students completed an activity comparing and contrasting photographs of life on a reservation. Throughout this activity, the students discussed the use of visual media to draw upon emotion, including emotions generated by romanticism and poverty. The activity also drew attention to the influence of the photographer/filmmaker on the creative process and final product. We asked students how films made by cultural outsiders might differ from those made by Native filmmakers, even if the location, subjects, and ideas are the same.

Despite these preparatory activities, both Native and non-Native students expressed anxiety about participation in the Project. One PWI student, in particular, was extremely reluctant to attend the first workshop, given her fear of being blamed. To promote collective agency and ally building, we encouraged students to think about ways to use filmmaking in response to White guilt and historical trauma. We also noted that the workshops offered a space for dialogue that is rarely available outside of collaboration between institutions of higher education. As a result of these efforts, we were able to convince even the hesitant PWI 
student to attend the first workshop.

To start the first workshop, participants introduced themselves, identified their goals for participation, and shared any ideas they had for film projects. As a whole group, we determined that the most important goal of the project was to elevate awareness of and respect for Indigenous experiences, histories, and perspectives. Tribal community members echoed the importance of increasing respect for Indigenous views, especially given the prevalence of predominantly White communities and institutions within the region.

Also during the first workshop, the TC participants shared powerful stories of struggle, persistence, and renewal (e.g. overcoming addiction, living in poverty, struggling with language and identity). These discussions allowed PWI participants to realize that challenges are situated within a complex socio-historical landscape. In addition, the trust and openness demonstrated by the TC participants helped the PWI students realize the importance of the Project and the willingness of the Native community to collaborate in cross-cultural contexts.

Midway through the workshop, the PWI student who had been reluctant to attend pulled a faculty leader aside to explain, "This isn't what I expected. I'm learning so much." At the conclusion of the workshop, an elder who had been collaborating with the student thanked her with a hug. This example demonstrates the complexity of respect within cross-cultural documentary storywork. Since many PWI students may lack a foundational understanding of Indigenous knowledges and ways of knowing, it is important to move beyond sharing examples of stereotypical or overly simplistic work without engaging students in dialogue with Indigenous peoples. Without the cross-cultural interaction, students tend to impose their own perspectives on the topic, which results in a focus on White guilt and inaction.

To sustain cross-cultural interaction throughout the Project, participants worked closely with tribal members from the community during each phase. For example, an elder provided the research topic idea for films, cultural leaders reviewed content and made recommendations, and completed films were shared with the public as part of a community-wide showcase on the reservation. In addition to honoring traditional models of leadership and mentorship, engagement and collaboration with various community members allowed the PWI participants to learn about cultural protocol within documentary filmmaking practice and research.

The PWI participants served as technical mentors who provided guidance for equipment and software use, as a means to support the Indigenous knowledges, values, and beliefs comprising the specific projects. For example, the PWI faculty members introduced a variety of documentary filmmaking modes, which allowed the TC participants to choose one or to blend several modes most appropriate to their chosen topic. When TC participants expressed concerns (e.g. "I don't like how distracting it is to see the people walking on the side"), the PWI participants provided technical guidance (e.g. "I can show you how to crop the frame to minimize that movement"). Throughout the Project, the PWI participants were coached in terms of using listening and questioning skills, instead of dictating and taking control of projects. 


\section{Relevance}

While the topics, methods, and products deemed relevant to a specific community may be unique, the process for promoting relevance can be considered across contexts. Kirkness and Barnhardt (2001) emphasize attention to aspects that are relevant for all Indigenous communities, such as spirituality, tradition, history, vitality, conflict, place, and transformation. For many Indigenous peoples, stories serve to sustain and revitalize memory, but they also serve as "meaningful, theory-full practice" (King, Gubele, \& Anderson, 2015, p. 9). In other words, storywork extends beyond the collection, interpretation, and dissemination of stories: It is a relevant and dynamic process grounded in Indigenous worldviews.

Each of the documentary topics focused on community interests. For example, a tribal elder who is one of the few remaining fluent speakers expressed her concern about the loss of Indigenous languages. She encouraged the TC participants to research the importance of language and to share the results through film. In addition to supporting relevance for the community, asking the tribal members to select topics helped promote trust. Although the topics were deeply emotional, the TC participants hoped the filmmaking process would allow an opportunity to confront personal and collective trauma. The PWI participants were "shocked at how willing [the TC participants] were to share really deep, personal stuff." The process proved to teach the emerging filmmakers about themselves and each other. While powerful, a focus on relevance also has the potential to, as one faculty researcher noted, "open old wounds."

In the Project, awareness of relevance extended beyond the selection of topics to procedural decisions (e.g. how to conduct interviews, what to include or exclude from final products, etc.). For example, workshops were planned based upon feedback from participants. When TC participants expressed an interest in additional interviewing practice, a workshop session focused on team practice with planning for interviews and using the equipment. At the end of the workshop, the TC participants had developed the confidence needed to interview the president of the tribal college. During selection of supplemental footage, the TC participants carefully reviewed historical photographs, paying attention to the names of people in the photos ("I know that is a [specific tribe] name"), places, and other visual cues (e.g. attire, tipis, etc.) in order to ensure relevance for the specific tribal community. Editing processes further demonstrated attention to culturally relevant decision-making. For example, TC participants noted that it was important to see the markings on the bottom of a tipi, given their cultural significance. When cropping an archival photo, the participants made sure the final product included a view of the markings.

Additionally, it was important to the participants and leaders that the process and products be shared in relevant ways with the broader tribal community. We provided an overview of the Six Rs and examples from the Project's workshops during a community showcase. Following the presentation, the TC filmmakers premiered one of the Project films. Research is rarely shared with the community in accessible formats, and film offers a powerful way to provide examples of research processes in action.

The PWI students and faculty struggled with the tenet of relevance in several ways. 
For example, it proved challenging to "hold back" as TC students created storyboards and edited projects. The desire to control these processes was likely informed by multiple factors, including a genuine interest in helping ease the learning curve for TC students, enthusiasm about the topic and teaching, and familiarity with making decisions related to filmmaking. After introducing explanations and examples of the Four Rs (Kirkness \& Barnhardt, 2001) at the start of the first workshop, the participants were invited to discuss additional values and principles to guide the Project. As a result, the TC participants added relationality and representation to the Project framework. From the first moments of the first workshop, the participants were reminded of the importance of centering the interests and values of the Native community throughout the Project.

\title{
Responsibility
}

Responsibility within Indigenous contexts holds broad meaning, including accountability to community members (including elders and youth), stewardship of place, and ethical attention to sustainability and revitalization of traditional knowledges (Kirkness \& Barnhardt, 2001; Kovach, 2009; Lomawaima, 2013; Wilson, 2008). Kovach (2009) explains that IRMs demand collective and ethical responsibility. In other words, decisions made by scholars affect individuals and communities. Furthermore, Indigenous research depends upon a critical orientation, which demands both knowledge and action (Brayboy, et al., 2012; Kovach, 2009). Researchers are expected to be purposeful with the knowledge they acquire: They must do something with the results of their work.

Throughout the Project, the participants demonstrated various perspectives of social responsibility. Although the PWI participants often choose film topics related to social issues, their ideas for topics typically reflect of individual interest, whereas the TC participants focus on the interests and perceptions of the broader tribal community. Along these lines, the TC participants recognized urgency for sharing the stories, as tied to collective healing. One TC participant noted,

\begin{abstract}
We're at a crucial time. We're risking the loss of our language and our culture. This [documentary project] comes at the right time to point us in the right direction for healing. Instead of carrying all that baggage by yourself, [hearing about the stories of others] lightens your load.
\end{abstract}

This sense of cultural responsibility also extended beyond topic selection and initial filming. For example, one TC participant emphasized the importance of sharing the interviews "in a good way." Such sharing demands a sophisticated understanding of cultural protocol, which is something few of the PWI participants think about in their day-to-day filmmaking work. For example, a TC participant noted, "We need to check with [a cultural leader] about that, because I don't know if we can use that." In another case, the TC participants were concerned that an interviewee's wording might offend elders in the community. While they wanted to honor the speaker's ideas, they were also keenly aware of the duty to honor tribal values,

Engaged Scholar Journal: Community-Engaged Research, Teaching and Learning 
such as respecting elders. For the TC participants, making such decisions was at the heart of demonstrating a responsibility to self and others in the community. Iseke and Moore (2011) call this a "kinship responsibility" that demands culturally responsive editing of digital stories (p. 33). For the PWI participants, new understanding of the complexity and importance of responsibility to the community has positioned them to advocate for adherence to cultural protocol within documentary work.

As a result of the Project, the TC participants developed technical skills needed to mentor other tribal members in future documentary filmmaking endeavors. Following the community showcase, several community members approached the filmmakers and research team to share ideas for future projects. Importantly, the TC participants did not view their responsibility as a burden, at least not as the Project unfolded. As one TC participant noted, "It [participation in the Project] started out as a workshop for credits. It turned out to be a new dream I didn't even know I had." For this participant, the Project offered a way to align educational goals with her responsibility to the community.

\section{Reciprocity}

Kovach (2009) notes that reciprocity is inseparable from respect and responsibility-in order to respect collective knowledge, one must take action that benefits the Indigenous community. Wilson explains that reciprocity is more than one-time gift-giving: It demands a sustained, interactive partnership. In order to support reciprocity, non-Indigenous faculty members and scholars must endeavor "to understand and build upon the cultural background of the students," while simultaneously supporting access for students "to the inner-workings of the culture (and the institution) to which they are being introduced" (Kirkness \& Barnhardt, 2001, p. 9). In the case of the Project, ensuring reciprocity meant honoring Indigenous knowledges and ways of knowing while expanding Indigenous participants' access to technical filmmaking skills and equipment.

Research and filmmaking within Indigenous communities has-historically-benefitted dominant culture researchers/filmmakers more than the communities themselves. Early in the workshop series, the TC and PWI participants and community members discussed examples from various documentaries, which allowed for a critique of the motivations of filmmakers. As they planned for their own filmmaking projects, the participants were thoughtful about ways to ensure meaningful, reciprocal relationships with the community. For example, during the first workshop, an elder asked, "What are you going to do with the films when we're done?" This question initiated a discussion about sovereignty, culturally sensitive content, and responsibility. Both the TC and the PWI participants realized that reciprocity is integrated with responsibility, as are many of the other Rs. In particular, for the TC participants, reciprocity is the outcome of a sense of collective responsibility.

Accountability to the community should extend throughout research and filmmaking projects. Since filmmakers are not always associated with academic institutions, they may not be expected to follow protocol for ethical research and creative activity. In this case, plans for the Project were reviewed and approved by Institutional Review Boards (IRBs) of both the 
PWI and the tribal nation. As part of the agreement with the tribe's IRB, participants were expected to share an overview of the process and resulting films, as deemed appropriate by the TC participants and tribal community members.

To further adhere to the tenet of reciprocity, the TC participants and tribal community members controlled decision-making about both the process and the final products. DVD copies of the film that premiered at the community showcase were given to the interviewees and several elders, and the film was uploaded to YouTube and shared through social media. In this example, the content was determined to be appropriate to share with the public, including non-Native viewers from outside of the community. The TC filmmakers chose to exclude ceremonial images and songs so the film could be disseminated more broadly. However, as previously discussed, although digitizing stories can expand access to Indigenous knowledges, and although expanded access can advance efforts to revitalize traditional knowledges, unrestricted access has the potential to compromise culturally sensitive content.

To support culturally sustaining/revitalizing education, benefits from research and filmmaking efforts must transcend the project's timeframe. One of the key goals of the Digital Histories Project was to develop Indigenous researchers and filmmakers who are able to serve the community beyond the project. In addition to developing films that can influence education within the community, the TC participants used their skills to film a community discussion, and they shared footage at events to honor a community member who had passed away.

Finally, attention to both the process and product advanced community-wide conversations about collaboration, Indigenous research, and education. As the TC faculty leader noted during the community showcase, the Project has the potential to be "history-making work" in that it engages Native student researchers in controlling community-based research and filmmaking processes and products. For the tribal college, the Project provides a model for cross-cultural research across disciplines.

\section{Representation}

King (2015) emphasizes that visual representations of Indigenous peoples by non-Native peoples have long been problematic, as they are rooted in fascination with the primitive other, savage, or "vanishing Indian" (p. 23). Today, mainstream media continues to perpetuate stereotypical Indigenous imagery. Through reclaimed representations, Indigenous peoples can sustain and revitalize cultural knowledges and epistemologies, a process Vizenor (2008) terms "survivance" (p. 1).

From the beginning of the Project, the leaders and participants considered the importance of appropriate representation. For example, during the first workshop, the participants discussed popular portrayals of Indigenous peoples in film and other visual media. They agreed that how Native experiences, histories, and peoples are represented affects the potential to sustain and/or revitalize cultural knowledges. This discussion generated interest in adding a fifth "R" - representation— to the Four Rs offered by Kirkness and Barnhardt (2001).

Thinking about representation proved transformative for PWI participants. Prior to the first workshop, several of the PWI students noted that they expected TC participants to 
engage in filming stories based upon romantic Indian imagery (e.g. powwows) or stereotypical reservation challenges (e.g. poverty, addiction, etc.). The PWI students were surprised by the personal connections: Instead of superficial romanticism or stereotyping, the TC projects demonstrated depth, authenticity, and complexity.

An example from the third workshop further illustrates the importance of honoring cultural perspectives in terms of representation. The TC and PWI participants were discussing how to break up interviews for a more appealing visual effect. A PWI student suggested weaving segments of a traditional song throughout an elder's account. Fading in and out of the song and the spoken words would better hold the viewer's interest, he argued. While the suggestion demonstrated attention to artistic quality, a TC participant explained that such a representation would potentially be disrespectful since neither song nor story would be fragmented in traditional storytelling contexts. This discussion resulted in a plan to consult cultural leaders prior to additional editing.

Decisions about representation were not limited to the specific content. For example, during the third workshop, one TC participant expressed her belief that the team should adhere to a linear storytelling structure, which is common within mainstream filmmaking and which the participant assumed is more "right" than nonlinear, culturally congruent structures. The team was encouraged to trust cultural perspectives in terms of organizing footage and developing the film's story arc. Toward the end of the editing process, the team selected a title for the film screened at the community showcase that recognizes the circular nature of Indigenous storytelling. In the end, the structure became a way to represent and honor Native ways of knowing.

As a TC participant noted, the digital storywork process offered a "culturally valid" means of disseminating interview data. Iseke and Moore (2011) explain "Indigenous digital storytelling challenges not only the stories of the dominant society but also oppose the exclusivity of textbased resources" (p. 34). One TC participant echoed this awareness by suggesting that "film has a more powerful impact [than books] . . It's recreating the oral tradition." Another TC participant also noted a connection to the oral tradition made possible through filmmaking: "[It] becomes more personal when you see the person telling the story. It's different from reading a book, where you can't see the person."

\section{Relationality}

Although Kirkness and Barnhardt (2001) did not specifically mention relationality as one of their "Rs", the participants emphasized its importance early in the first workshop, and it is emphasized across much of the Indigenous research literature (Kovach, 2009; Wilson, 2008). It is important to note that the term relationality is multi-dimensional. Indigenous scholars explain that First Nations knowledges and ways of knowing are cyclical and interrelated (Wilson, 2008). Brayboy (2005) explains the critical orientation of the "dialogical relationship between culture, knowledge, and power: culture is the base for knowledge that ultimately leads to power" (p. 436). In addition to relationships between aspects of knowledge, there are also relationships among and between individuals, communities, governments, and the land 
(Brayboy, 2005; Kovach, 2009). Therefore, Wilson (2008) argues for "relational accountability" (i.e. accountability to various members of the community with whom scholars should have sustained and respectful relationships) throughout scholarly endeavors.

The Project would not have been possible without a focus on relationship building between participants and between faculty leaders. While the Project itself spanned a short timeframe, it was built upon pre-existing relationships between members of the leadership team. The PWI and TC faculty leaders have collaborated for several years. Given their membership in a small, close-knit community, many of the TC students knew each other before joining the Project. However, the depth of the TC participant relationships varied (e.g. some participants were closely related to each other, while two were returning to the reservation after growing up in other communities).

The Project provided opportunities for PWI and TC participants to learn from and with each other. Several TC and PWI participants chose to work throughout multiple workshops and to remain connected outside of the workshops. As a result, participants developed trust and confidence. For example, a TC student who was intimidated by the interview process partnered with a PWI student for the majority of the third workshop. The individualized attention provided opportunities for the TC student to build confidence in her interviewing and filming skills, while the partnership allowed the PWI student to become comfortable asking questions about cultural topics. Social media has allowed participants-even those who have graduated - to remain connected with others who were involved in the Project.

The learning was not limited to interactions between TC and PWI participants, though. Project efforts transcended generational lines, as participants worked with tribal elders and youth. For example, a film focusing on language revitalization included interviews with community members from various generations, which demonstrated the importance of Indigenous language to people of different ages. Multi-generational storywork can be a powerful approach for culturally sustaining and revitalizing education (Iseke and Moore, 2011).

The PWI students and faculty developed a new awareness of relationality within research and filmmaking practice as a result of the Project. During the second workshop, a TC participant tentatively asked if it was acceptable for filmmakers from different teams to share footage. This request demonstrated the importance of relationality between participants and between elements of knowledge. The PWI film instructor noted that her students rarely, if ever, consider sharing footage. The TC students, however, had a difficult time imagining not sharing experiences, resources, and understandings, since those knowledges overlap in daily life.

Early in the workshop series, the PWI faculty leaders were challenged in terms of relationality. At the start of the second workshop, a TC faculty member expressed concerns about the formal workshop space located on the PWI campus. While the space supported collaboration and technology use, working in an institutional setting generated some discomfort and inhibited trust building. The TC faculty member explained that traditionally learning occurs in informal environments within the tribal community. To address this concern, the PWI faculty leaders hosted a group meal at a leader's house. The setting provided an opportunity for more relaxed

Engaged Scholar Journal: Community-Engaged Research, Teaching and Learning 
conversation surrounding the sharing of cultural knowledges. The evening also supported recognition of the TC faculty member's leadership.

While the Project provided opportunities for the PWI and TC students to get to know each other both within and beyond the research setting, it is important to note that the Project is only the beginning of the relationship. Work is underway to sustain the Project within the tribal college, expand to other communities and institutions, and prepare students and faculty who can provide on site technical mentoring in tribal communities.

\section{Conclusion: Implications for Community-Engaged Scholarship}

The Digital Histories Project offers multiple insights related to community-engaged research. First, the Project presents documentary storywork as an approach to advance culturally sustaining/revitalizing research and education. Even in short timeframes, it appears possible for documentary filmmaking to provide meaningful learning for both Native and nonNative participants. To determine long-term outcomes, the faculty leaders plan to continue to communicate with Project participants through social media. We hope to explore if/how participants apply the Six Rs as they develop documentaries with diverse communities, even after they graduate from the PWI or TC.

A second insight relates to the collaborative potential for storywork. Cross-cultural contexts complicate understandings of responsibility, since scholars and filmmakers may feel responsible to individuals they portray, to communities, to multiple generations, to diverse audiences, and/ or to society at large in different ways. Community-centered participatory research may offer a model for thinking more comprehensively and holistically about responsibility. Of course, the Project also offers examples of limitations in terms of responsibility, given its short-term implementation and its small number of participants from the tribal and PWI communities.

The Project leaders learned important lessons from the initial workshop series. Most importantly, we are interested in finding new ways to more effectively support TC participants between workshops. The TC participants noted a lack of confidence, especially in terms of the editing process. A structured and institutionalized program, such as a filmmaking course at the TC, could provide more incremental guidance and benchmarks to support individual and team progress. However, it will be important to also honor the different views of progress within the community. For example, one TC participant was eager to try using the equipment and software, even if he made mistakes. Other TC participants were more reflective; they wanted to observe and then practice in private before working with the PWI students.

Finally, meaningful incorporation of Indigenous storywork within the Academy offers an opportunity to counter settler-colonial narratives, connect with communities, and integrate Indigenous values into research and education (Clark, 2004). Within higher education, there is a growing interest in developing and sharing participatory and culturally responsive research methods. This interest is due, in part, to a "nation-building renaissance" occurring in Indigenous communities, which has resulted in increased expectations for Indigenous-led decision-making and tribal research sovereignty during university collaborations (Norman \& Kalt, 2015, p. 3). In addition, funding agencies are more frequently encouraging work that 
strives to advance social justice, especially through the use of digital media. Unfortunately, there is also a potential for digital media to "commodify" culturally sensitive content (Smith, 2005, p. 95), since such media can expand access for members of the public beyond the specific tribal community. Therefore, it is critical for filmmakers and scholars to consider the potential for research and filmmaking to either advance or restrict tribal sovereignty with regards to cultural knowledges.

Kirkness and Barnhardt (2001) encourage both institutional and community-level responsibility in terms of promoting culturally sustaining/revitalizing education and research. In particular, institutions can advance Indigenous educational self-determination by involving community leaders in the design and enactment of mission and vision statements. The same concept can apply within cross-cultural research. In the case of the Digital Histories Project, members of the Indigenous community initiated the project design and contributed to ongoing planning and evaluation. It is important to note that, to be meaningful and fulfill the expectations of the $6 \mathrm{Rs}$, leaders and participants must walk the talk of their culturally sustaining/revitalizing mission or vision. As Kovach (2009) argues, responsible scholarship requires both knowledge and action. In the Project, we regularly revisited our goals, then noted specific actions that aligned with or distracted from those goals so we could make adjustments.

Since stories are "all we know" (King, 2003, p. 2), learning from and through crosscultural storywork may offer a way to recognize Indigenous sovereignty and raise social justice awareness for non-Indigenous participants. In particular, the Project highlighted in this article demonstrates the potential for the Six Rs (respect, relevance, reciprocity, responsibility, relationality, and representation) to promote culturally sustaining and revitalizing communityengaged storywork with/in Indigenous communities.

\section{About the Authors}

Brad Hall is a vice president at Blackfeet Community College, a tribal college on the Blackfeet Indian Reservation. His interests focus on Piikani leadership and the use of innovative practices to support traditional Indigenous values across educational contexts. Hall has also worked as a teacher and administrator in tribal communities.

Lucia Ricciardelli is an assistant professor in the School of Film and Photography at Montana State University. Her interests focus on representations of class, race, and gender in visual media. Ricciardelli recently published a book, American Documentary Filmmaking in the Digital Age: Depictions of War in Burns, Moore, and Morris. 
Christine Stanton (corresponding author) is an assistant professor of Education at Montana State University. She has published in journals such as Equity \& Excellence in Education, Theory \& Research in Social Education, and Qualitative Inquiry. Stanton's interests focus on communityconscious education, teaching with Indigenous histories, and participatory research to advance social justice. Email: christine.rogers1@montana.edu

\section{References}

Archibald, J. (2008). Indigenous storywork: Educating the heart, mind, body, and spirit. Vancouver: UBC Press. Brayboy, B. M. J., Gough, H. R., Leonard, B., Roehl, II, R. F., \& Solyom, J. A. (2012). Reclaiming scholarship: Critical Indigenous research methodologies. In S. D. Lapan, M. T. Quartaroli, \& F. J. Riemer (Eds.). Qualitative research: An introduction to methods and designs (pp. 423-450). San Francisco: Jossey-Bass.

Brayboy, B. (2005). Toward a tribal critical race theory in education. The Urban Review, 37(5), 425-446.

Clark, D. A. T. (2004). Not the end of the stories, not the end of the songs: Visualizing, signifying, counter-colonizing. In D. A. Mihesuah \& A. C. Wilson (Eds.), Indigenizing the academy: Transforming scholarship and empowering communities (pp. 218-232). Lincoln: University of Nebraska Press.

Emerson, R. M., Fretz, R. I., \& Shaw, L. L. (1995). Writing ethnographic fieldnotes. Chicago: University of Chicago Press.

González, N., Moll, L. C., \& Amanti, C. (2005). Funds of knowledge: Theorizing practice in households, communities, and classrooms. Mahwah, N.J.: L. Erlbaum Associates.

Grande, S. (2008). Red pedagogy: The un-methodology. In N. K. Denzin, Y. S. Lincoln, \& L. T. Smith (Eds.) Handbook of critical and Indigenous methodologies (pp. 233-254). Los Angeles, CA: Sage.

Gruenewald, D. A. (2003). Foundations of place: A multidisciplinary framework for place-conscious education. American Educational Research Journal, 40(3), 619-654.

Harris, A. (2010). Race and refugeity: Ethnocinema as radical pedagogy. Qualitative Inquiry, 16(9), 768777.

Iseke, J., \& Moore, S. (2011). Community-based Indigenous digital storytelling with elders and youth. American Indian Culture and Research Journal, 35(4), 19-38.

Israel, B., Schulz, A., Parker, E., \& Becker, A. (1998). Review of community-based research: Assessing partnership approaches to improve public health. Annual Review of Public Health, 19, 173-202.

Kilpatrick, N. J. (1999). Celluloid Indians: Native Americans and film. Lincoln, NE: University of Nebraska Press.

King, L. (2015). Sovereignty, rhetorical sovereignty, and representation: Keywords for teaching Indigenous texts. In L. King, R. Gubele, \& J. R. Anderson (Eds.) Survivance, sovereignty, and story: Teaching American Indian rhetorics (pp. 17-34). Boulder, CO: The University Press of Colorado. 
King, L., Gubele, R., \& Anderson, J. R. (2015). Introduction: Careful with the stories we tell/Naming survivance, sovereignty, and story. In L. King, R. Gubele, \& J. R. Anderson (Eds.) Survivance, sovereignty, and story: Teaching American Indian rhetorics (pp. 3-16). Boulder, CO: The University Press of Colorado.

King, T. (2003). The truth about stories: A Native narrative. Minneapolis, MN: University of Minnesota Press.

Kirkness, V. J., \& Barnhardt, R. (2001). First Nations and higher education: The four R's—Respect, relevance, reciprocity, responsibility. In R. Hayoe \& J. Pan (Eds.) Knowledge across cultures: $A$ contribution to dialogue among civilizations. Hong Kong: The University of Hong Kong. Retrieved from http://www.ankn.uaf.edu/IEW/winhec/FourRs2ndEd.html

Kovach, M. (2009). Indigenous methodologies: Characteristics, conversations, and contexts. Toronto: University of Toronto Press.

Kovach, M. (2013). Treaties, truths, and transgressive pedagogies: Re-imagining Indigenous presence in the classroom. Socialist Studies, 9(1), 109-127.

Lomawaima, K. T. (2013). Relationships and responsibilities. Anthropology \& Education Quarterly, 44(1), $11-14$.

McCarty, T. \& Lee, T. (2014). Critical culturally sustaining/revitalizing pedagogy and Indigenous education sovereignty. Harvard Educational Review, 84 (1), 101-124.

McGregor, S. L. T. \& Murnane, J. A. (2010). Paradigm, methodology, and method: Intellectual integrity in consumer scholarship. International Journal of Consumer Studies, 34(4), 419-427. Retrieved from http://www.consultmcgregor.com/documents/research/Methodologicalpaper-2010-for-web.pdf

Norman, D. K. \& Kalt, J. P. (2015). Native nations and universities: Collaborative strategies for nation building. In D. K. Norman \& J. P. Kalt (Eds.) Universities and Indian country (pp. 3-14). Tucson, AZ: University of Arizona Press.

Northway, R. (2010). Participatory research: Part 1: Key features and underlying philosophy. International Journal of Therapy and Rehabilitation, 17(4), 174-179.

Paris, D. (2012). Culturally sustaining pedagogy: A needed change in stance, terminology, and practice. Educational Researcher, 41(3), 93-97.

Rubin, H., \& Rubin, I. (2005). Analyzing coded data. In H. Rubin \& I. Rubin, Qualitative interviewing: The art of hearing data ( $2^{\text {nd }} \mathrm{Ed}$.) (pp. 224-245). Thousand Oaks, CA: SAGE.

Seixas, P. (2007). Popular film and young people's understanding of the history of Native-White relations. In A. S. Marcus (Ed.) Celluloid blackboard: Teaching history with film (pp. 99-120). Charlotte, NC: Information Age Publishing.

Smith, L. T. (2005). On tricky ground: Researching the Native in the age of uncertainty. In N. K. Denzin \& Y. S. Lincoln (Eds.), The Sage handbook of qualitative research ( $3^{\text {rd }}$ ed., pp. 85-107). Thousand Oaks, CA: Sage.

Smith, L. T. (1999). Decolonizing methodologies: Research and Indigenous peoples. New York: Zed Books.

Stoddard, J., Marcus, A., \& Hicks, D. (2014). The burden of historical representation: The case of/for Indigenous film. The History Teacher, 48(1), 9-36.

Stanton, C. R. (2014). Crossing methodological borders: Decolonizing community-based participatory research. Qualitative Inquiry, 20(5), 573-583.

Vizenor, G. (2008). Aesthetics of survivance: Literary theory and practice. In G. Vizenor (Ed.) Survivance: Narratives of Native Presence (pp. 1-24). Lincoln, NE: University of Nebraska Press.

Engaged Scholar Journal: Community-Engaged Research, Teaching and Learning 
Willie, S. (2003). Acting black: College, identity, and the performance of race. New York, NY: Routledge. Wilson, S. (2008). Research is ceremony: Indigenous research methods. Black Point, Nova Scotia: Fernwood Publishing. 